of the disease is minimal, deaths are few, and the costs of such vaccinations would be enormous. Even if immunisation gave $100 \%$ protection, some 500000 tourists would need to be immunised to prevent one imported case of cholera-and it would be extremely difficult to propagate immunisation in citizens of endemic countries. Given that the cost per vaccination is around US $\$ 10$ (including consultation), each prevented case of cholera would cost 5 million dollars.

Immunisation against cholera should therefore be reserved for the high-risk groups mentioned initially, ${ }^{2}$ mainly for medical staff taking care of patients, and additionally for laboratory workers exposed to the vibrio. Whenever a certificate of cholera immunisation is required from other travellers, a single dose of vaccine is sufficient as a mere formality. ${ }^{2}$

We are grateful to Miss E Herold for administrative help and to Mrs Beth Urech for her English corrections. We also acknowledge the help of the health authorities of the different countries, without whom it would have been impossible to collect the valuable epidemiological data.

\section{References}

${ }^{1}$ Manson-Bahr PEC, Apted FIC. Manson's tropical diseases. 18th ed. London: Baillière, Tindall, 1982.

2 US Department of Health and Human Services. Health information for international travel 1981. MMWR 1981 ;suppl:64-5.

${ }^{3}$ World Health Organisation. Vaccination certificate requirements for international travel and health advice to travellers. Geneva: World Health Organisation, 1982:7.

${ }^{4}$ Bins M, Peeters M, Meuwese J. Een patiente met cholera in Nederland. Ned T Geneesk 1978;122:668-71.

${ }^{5}$ Snyder JD, Blake PA. Is cholera a problem for US travellers ? $\mathcal{f} A M A$ $1982 ; 247: 2268-9$

- Apothéloz M, Grob PJ, Steffen R, Schar M. Welchen Auslandreisenden ist ein Impfschutz gegen Hepatitis zu empfehlen? Soz Praeventivmed $1982 ; 27: 264-5$.

7 Steffen R. Typhoid vaccine, for whom ? Lancet 1982;i :615-6.

${ }^{8}$ Steffen R, van der Linde F, Meyer HE. Erkrankungsrisiken bei 10,500 Tropen- und 1,300 Nordamerika-Touristen. Schweiz Med Wochenschr 1978;108:1485-95.

${ }^{9}$ Anonymous. Susceptibility to cholera. $B r$ Med $\mathcal{F} 1975$;iv : 423.

${ }^{10}$ Public Health Service. Cholera vaccine. MMWR 1978;27:173-4.

\title{
Therapeutic retraction of the foreskin in childhood
}

\author{
GRAHAM G COOPER, GEORGE J L THOMSON, PETER A M RAINE
}

\begin{abstract}
A retrospective study was conducted of 91 boys who had had a non-retractable but non-fibrosed prepuce treated by retraction under general anaesthesia. Of the 79 boys who had had symptoms, $67(85 \%)$ obtained relief. Twelve of the 91 patients were later circumcised because of continuing problems.

Retraction of the foreskin alone is a simple and effective alternative to circumcision in managing most boys with a symptomatic, non-retractable prepuce.
\end{abstract}

\section{Introduction}

It is perhaps surprising that a surgical procedure with a history extending almost 4000 years can still be a subject of controversy, yet this is true of circumcision in childhood. Fibrous stenosis of the preputial orifice remains a clear indication for circumcision, but this is not a common condition in the first decade of life. In this age group, a foreskin which cannot be retracted over the glans is more often due to delay in the natural process by which these structures become separate and is not necessarily a pathological condition. ${ }^{1}$ None the less, it may be associated with urinary symptoms or attacks of balanoposthitis, which may be aggravated by the process of separation itself. Excision of the foreskin because it has not yet become detached from the glans is a radical measure, though it is common for boys to be referred to a surgeon with this request.

Acceleration of the natural processes by formally retracting the prepuce under general anaesthesia is a logical approach to the problem of relief of symptoms due to a non-retractable,

Royal Hospital for Sick Children, Glasgow G3 8SJ

GRAHAM G COOPER, MB, FRCS, surgical registrar (now registrar, department of surgery, Western Infirmary, Glasgow)

GEORGE J L THOMSON, MB, FRCS, surgical registrar (now registrar in general surgery, Southern General Hospital, Glasgow)

PETER A M RAINE, MB, FRCS, consultant surgeon non-fibrosed foreskin in childhood. Review of the world literature over the past decade, however, yielded only one reference to the procedure. ${ }^{2}$ We have reviewed the experience of the surgeons at this hospital in the use of the technique and its results over the past six years.

\section{Patients and methods}

Between January 1976 and March 1982, 106 boys underwent retraction of their foreskin under general anaesthesia. Of these, 93 had presented with symptoms and 13 had been referred because of a non-retractable foreskin alone (see table).

Retraction was performed at ages ranging from 6 months to 11 years 11 months (mean 4 years 9 months). Adhesions between prepuce and glans were separated carefully by traction using a gauze swab or by gentle sweeping with a probe. Collections of desquamated material were removed from the subpreputial space and petroleum jelly applied. In 10 cases the prepuce was stretched with forceps. In many cases the parents were asked to retract their child's foreskin and reapply petroleum jelly daily for a week after the operation.

From a review of the case records 13 boys were found to have been circumcised at a later stage. Information on 78 of the remaining 93 patients was obtained at a review clinic (54), by questionnaire to the parents (14), or by letter from their general practitioner (10). Questions were asked about the outcome of the procedure and a gentle attempt made to retract the foreskin. Fifteen boys were lost to follow-up.

For comparison, the complications occurring after 100 circumcisions selected at random from those performed in 1980 were studied retrospectively. The indications for circumcision were non-retractable foreskin, balanoposthitis, urinary symptoms, and phimosis. The mean age at operation was 4 years 11 months. The technique used was excision of the foreskin and wound closure with interrupted absorbable sutures.

\section{Results}

The table gives the outcome of the procedure in relation to the presenting features. Of the 79 boys with symptoms, $67(85 \%)$ had obtained relief. Information on retractability of the foreskin was obtained in 73 boys, and in $45(62 \%)$ of these it was fully retractable. 


\begin{tabular}{|c|c|c|c|c|c|c|c|c|c|}
\hline \multirow[b]{2}{*}{ Presenting complaint } & \multirow[b]{2}{*}{ Total No } & \multirow{2}{*}{$\begin{array}{l}\text { No lost } \\
\text { to follow-up }\end{array}$} & \multicolumn{3}{|c|}{ Symptoms } & \multicolumn{3}{|c|}{ Retractability of foreskin } & \multirow{2}{*}{$\begin{array}{c}\text { No } \\
\text { subsequentl } \\
\text { circumcised }\end{array}$} \\
\hline & & & Abolished & Improved & Unchanged & Complete & Incomplete & Not known & \\
\hline $\begin{array}{l}\text { Balanoposthitis } \\
\text { Dysuria } \\
\text { Ballooning of prepuce } \\
\text { Retained subpreputial smegma } \\
\text { Haematuria }\end{array}$ & $\begin{array}{r}56 \\
30 \\
20 \\
10 \\
4\end{array}$ & $\begin{array}{l}7 \\
7 \\
4 \\
0 \\
2\end{array}$ & $\begin{array}{r}38 \\
13 \\
7 \\
6 \\
1\end{array}$ & $\begin{array}{l}9 \\
4 \\
2 \\
3 \\
1\end{array}$ & $\begin{array}{l}2 \\
6 \\
7 \\
1 \\
0\end{array}$ & $\begin{array}{r}30 \\
7 \\
5 \\
7 \\
1\end{array}$ & $\begin{array}{l}9 \\
7 \\
6 \\
1 \\
0\end{array}$ & $\begin{array}{r}17 \\
16 \\
9 \\
2 \\
3\end{array}$ & $\begin{array}{l}4 \\
4 \\
3 \\
2 \\
1\end{array}$ \\
\hline $\begin{array}{l}\text { Total symptomatic group } \\
\text { Non-retractable prepuce alone }\end{array}$ & $\begin{array}{l}93 \\
13\end{array}$ & $\begin{array}{r}14 \\
1\end{array}$ & 54 & 13 & 12 & $\begin{array}{r}42 \\
3\end{array}$ & $\begin{array}{r}23 \\
5\end{array}$ & $\begin{array}{c}28 \\
5\end{array}$ & $\begin{array}{r}11 \\
2\end{array}$ \\
\hline Total & 106 & 15 & & & & 45 & 28 & 33 & 13 \\
\hline
\end{tabular}

In 19 of the 28 patients whose prepuce remained incompletely retractable symptoms had been improved by the procedure; nine of these 28 boys were later circumcised. Five of the eight boys examined who had presented with a non-retractable prepuce alone still exhibited a degree of this, and two were circumcised as a result. None developed symptoms consequent on retraction. The age at operation had no clear effect on the outcome. The follow-up interval ranged from one month to six years and one month, with a mean of one year seven months.

Altogether 13 boys were circumcised. In 12 cases the result of retraction was considered to be unsatisfactory due either to symptomatic recurrence (eight cases) or to persistent non-retractability of the foreskin (four). The remaining child had a redundant dorsal prepuce associated with coronal hypospadias but had had a perfect result from retraction. The mean age at circumcision of the 12 "failures" was 5 years 10 months, and the mean interval since retraction was 11 months.

Of 100 boys undergoing primary circumcision, seven had troublesome complications; two children required reoperation to arrest haemorrhage from the wound, four developed wound infections, and one had severe dysuria associated with a meatal ulcer.

\section{Discussion}

The work of Gairdner ${ }^{1}$ and $\varnothing$ ster $^{3}$ has resulted in a clearer understanding of the normal development of the foreskin. A common layer of squamous epithelium between the glans and the deep surface of the prepuce is the reason why $96 \%$ of male neonates have a non-retractable foreskin. As keratinisation of the epithelial layer occurs, the prepuce gradually becomes detached from the glans and retractable over it. This process has been completed by the age of 5 in about $90 \%$ of boys.

The term phimosis (Greek: "muzzled") may, semantically, be used to describe either the normal state of non-separation of the prepuce from the glans or fibrous stenosis of the preputial orifice, but this leaves ambiguity. We prefer to use "nonretractable foreskin" for the former state and "phimosis" for the latter, which we regard as pathological and relatively uncommon.

Some boys are referred for a surgical opinion simply because they have a non-retractable prepuce, but most have associated symptoms. We believe that the process of natural separation of the foreskin itself plays a part in the genesis of pain and inflammation by exposing incompletely epithelialised surfaces to urine and bacterially populated smegma. Ballooning of the foreskin during micturition has been attributed to malalignment of the external urethral meatus and the preputial orifice ${ }^{1}$ and may arise solely because of the length and laxity of the foreskin. When phimosis is not present, retraction of the foreskin under anaesthesia is a logical means of relieving symptoms, yet it receives little attention in the standard textbooks of paediatric surgery; in our series 67 out of 79 patients with symptoms $(85 \%)$ benefited from it.

The best way to differentiate a non-retractable from a phimotic foreskin is to draw it anteriorly away from the glans, as suggested by Spence. ${ }^{4}$ In almost every case this shows an adequate preputial orifice. If symptoms are mild the parents are reassured with an explanation of normal development and the child kept under review to allow natural separation of the foreskin, failing which retraction under anaesthesia at about 5 years of age is advised. We believe that a case can also be made for therapeutic retraction in an asymptomatic child of 5 years or more on the grounds that it facilitates bathing of the area.

The procedure requires only brief admission to hospital and causes very little discomfort. Gentleness is important, and stretching of the prepuce is unnecessary and possibly harmful. Applying petroleum jelly may relieve immediate postoperative discomfort and lessen the chance of readhesion, but some parents find this difficult and distasteful.

Circumcision in childhood carries a risk of complications: Index Medicus has listed 21 case reports in English of the more exotic post-circumcision problems over the past decade but we were unable to find a recently published series of circumcisions with which to compare our results. Complications disrupted the convalescence of seven patients in our review of 100 cases. Unless the need for circumcision subsequent to retraction is attributed to this procedure, therapeutic retraction of the foreskin was without complication.

In conclusion, retraction of the foreskin under general anaesthesia is a simple and effective alternative to circumcision in most boys with symptoms due to a non-retractable prepuce. We recommend its wider use.

We thank Mr A A F Azmy, Mr J F R Bentley, Mr W Cochran, Mr I $\mathrm{K}$ Drainer, and $\mathrm{Mr} \mathrm{D} \mathrm{G}$ Young for permission to study their patients, and Miss A Sharp for typing the manuscript.

Requests for reprints should be addressed to: Mr Graham G Cooper, Department of Surgery, Western Infirmary, Glasgow G11.

\section{References}

1 Gairdner D. The fate of the foreskin. Br Med F 1949;ii:1433-7.

2 Barbosa MG, Gonzalez CA, Alipaz A, Sanches JLG. La balanolisis como sostituto de la circumcision. Salud Publica Mex 1976;18:893-9.

3 Øster J. Further fate of the foreskin. Arch Dis Child 1968;43:200-3.

4 Spence J. Spence on circumcision. Lancet 1950;ii:902.

(Accepted 2 November 1982)

\section{Corrections}

Assessment of the accuracy and role of self-recorded blood pressures in the management of hypertension

An error occurred in fig 3 of the paper by Dr Brian A Gould and colleagues (11 December, $p$ 1691). On the abscissa times of day (hours) should have read: $0900,1100,1300,1500,1700,1900,2100,2300,0100,0300$, $0500,0700,0900$.

\section{Management of traumatic intracranial haematoma}

In this paper by Professor G Teasdale and colleagues (11 December, p 1695) the following acknowledgment was omitted: "This study was part of the MRC head injury research programme." 